\title{
Consortium Building in Enterprise Networks to Design Innovative Products
}

\author{
Marcus Seifert, Klaus-Dieter Thoben and Patrick Sitek \\ Bremen Institute of Industrial Technology and Applied Work Science, \\ Bremen, Germany \\ Contact: sf@biba.uni-bremen.de \\ Tel. +49-(0)421-2185547
}

\begin{abstract}
The potential of an Enterprise Network is the ability to design and to realize innovative, customized products by selecting and integrating for each order the worldwide leading partners. To exploit this potential, it is too late to configure the network and to search for partners on the basis of an already specified bill of material: Co-operation has already to start with the product-idea, where possible contributions to the planned end-product must be identified while concretizing the bill of material. Only in this way, the network is able to benefit from the expertise of all potential partners and to ensure that the expertise of the planned consortium is also synchronized with the needed capabilities for the requested end-product. In the proposed paper, a method to support the building of consortia within Enterprise Networks on the basis of open product designs will be highlighted. The method starts from an endproduct and collects possible contributions from potential collaboration partners.
\end{abstract}

\section{Keywords}

Virtual organizations, Product design, Consortium building, partner selection

\section{Introduction}

Market success under a worldwide competition depends more and more on the ability to provide customized products. The increasing complexity of these products led to the situation that capital intensive, complex investment goods are almost realized in co-operation between many partners. The single partner focuses on its core competencies while the process diversity is ensured by co-operation. Competition does not happen any more between single companies but between 
consortia (Boutellier 1999, S.66). The ability to form excellent co-operations is an important asset for the today's production.

\subsection{Collaboration in Enterprise Networks}

The today's opportunity to have a worldwide access to resources and capacities enables companies for the first time in history to select for each business opportunity the best suitable partners to fulfill highly customized customer orders. Companies are not dependent any more on existing relationships or regional suppliersinformation and communication technologies as well as high performing logistics capabilities encourage the global business which means serving worldwide distributed customers on the one hand and benefiting from global resources and capacities for production on the other hand. The collaboration of legally independent, equal companies in a network to generate customer specific products has been introduced as Enterprise Network. If these networks are short term and dynamic in terms of members, they are called Virtual Organizations (Sydow 2002, p.270).

Within Virtual Organizations, the capability to optimize the existing process chains in a continuous way as required in stable Supply Chains is not any more the main asset. It is rather critical to be able to identify and to select for a certain order the most appropriate partners and to establish in a very efficient way a high performing co-operation (Kemmner 1999, p.33). The today available approaches to identify and to select partners are mainly focusing on the production phase which means that the search and selection criteria are focusing on a companies' capability to provide excellent processes and to integrate themselves into a networked organization. This means that the consortium building process is linked with the realization of an already defined product and founded on an existing bill of material of the desired end-product.

The purpose of the existing approaches can be described as way to set-up high performing production networks. In consequence, many approaches which have been developed in the past provide a wide range of criteria and key performance indicators (KPIs) which are focusing on the performance of companies and their production processes. KPIs are almost the basis for a structured partner search and evaluation. But the approach to select partners according to their process performance does only consider mainly one phase of the product life cycle which is the production phase. This does always lead to optimization tasks to select the best performing partners for a pre-defined set of processes to provide already specified components or subsystems. The other phases of the product life cycle like the conceptual phase or the after sales phases do have completely different requirements for the partner selection. A service partner for the product support e.g. may be regionally close to the customer. This example illustrates that it is not sufficient to select partners on the basis of their production/process performance.

\subsection{The conceptual phase as potential for Enterprise Networks}

In Enterprise Networks, the phase with the highest potential is the conceptual phase. Enterprise Networks, esp. Virtual Organizations, do mainly provide complex and 
customized investment goods (Linde 1997, S.25) which can be described as engineer-to-order products. Considering this aspect, the conceptual phase where the concrete design of the end-product is not defined yet and where the bill of material is rather vague is the phase of the product life cycle with the highest potential for the consortium building: In the conceptual phase, there are still most of the degrees of freedom for the involvement of partners and the design of innovative products.

The chance within Enterprise Networks during the conceptual phase is to be able to enrich and improve the product design by involving the experience and competencies of all potential partners with the challenge to realize excellent products. Free from long-term contracts with suppliers and static processes, Enterprise Networks have the chance to incorporate the worldwide existing expertise into new product designs which enable the network to serve the market with highly customized and reliable products.

This means that it is not the main purpose in the conceptual phase to optimize resources and processes or to identify available capacities but to identify potential beneficial product contributions to the planned end-product and capabilities of possible partnerships. The objective should be to integrate potential partners very early for the concretion of the end-product. Only in this way, possible product innovations can be developed and competencies as well as experiences of all potential partners can be used to concretize the end-product. The chance to get to innovative solutions depends on the ability to gather the knowledge of promising partners already during the conceptual phase: Starting to search for partners when setting up the supply chain means to miss the opportunity to benefit from the knowledge and experience of potential partners for the product design.

Today, it can be recognized that many product designs are not developed from the scratch. Also complex engineer-to-order products are partly composed of available sub-systems and components which have to be adapted and integrated into the new design. Many companies are providing products which are explicitly foreseen to become parts of more complex systems. For example today's mobile phones containing touch-screen, GPS, UMTS and wireless-LAN units on a Windows Mobile platform do only combine and integrate existing sub-systems and components which are available as trading goods on the market and therefore normally well described and known. The main task is to identify beneficial sub-systems to develop innovative products and to integrate them into the planned design.

The ability to make use of those available sub-systems also in complex product designs enables companies in principle to evaluate potential partnerships already during the conceptual phase of the end-product. Against this background, the ability to identify potential contributions to a planned end-product and to initiate very early commercial relationships becomes a crucial asset for Virtual Organizations. This means that beside the evolution of production chains, the fast establishment of temporary trade relations will become more and more important for successful cooperations. 


\section{State of the Art: Existing approaches for consortium building}

The process of consortium building can be divided into two phases which are (1) partner search and (2) partner selection (Mertins, Faisst 1995, p.61ff.). The purpose of the partner search is to identify potential co-operation partners for a specific task within a specific phase of the product life cycle while the objective of the partner selection is to evaluate these potential co-operation partners and to decide for a consortium. Literature and practice provide many methods to support the consortium building. In the following, the most important concepts will be highlighted and structured according the product life cycle shown in Figure 1.

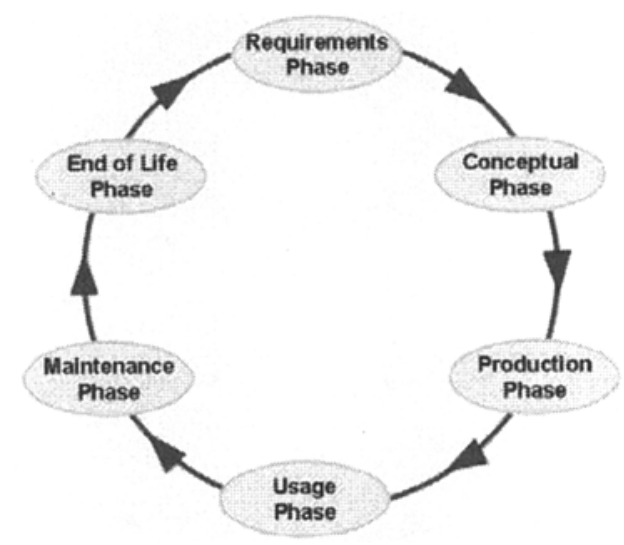

Fig. 1. Product life cycle

\subsection{Existing methods for the partner search}

Each of the product life cycle phases has different degrees of freedom regarding the partner search: The more indefinite the product design, the larger the pool of potential partnerships. While concretizing the product design and the bill of material, the requirements regarding process capabilities of potential partners and component design become more specific. This leads automatically to a reduction of possible choices for partners. Figure 2 shows the interdependency between the potential partnerships and the product life cycle.

According to Zahn, existing relationships between companies are still the main source for the partner search (Zahn 2001, p.60). This means that companies rely on existing co-operations and try to continue the business with well known suppliers. The decision for co-operation almost bases on private contacts of the company owners (Hoebig 2002, p.43). In consequence, the partner selection process can't be focused on excellent partnerships, but on the maintenance of established bilateral contacts. The advantage of selecting well known partners is the already existing trust 
between the parties. Disadvantage is on the other hand the reduction on a small group of potential partners which makes it improbable to find the best suitable partner and which impedes the consideration of the available potentials to improve the planned product.

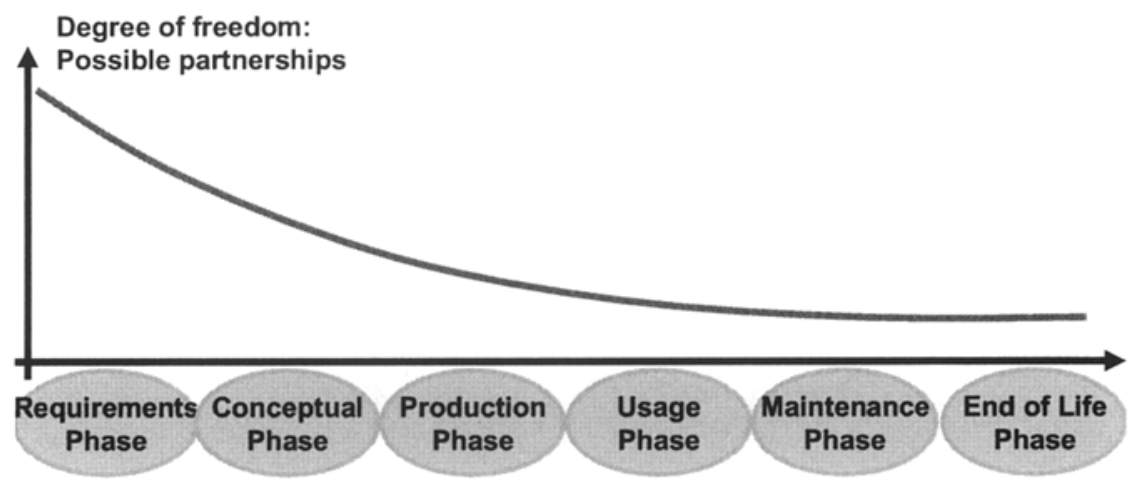

Fig. 2. Potential partnerships during the product life cycle

Alternative concepts coming from literature to search for partners in a more structured way are information brokers and co-operation databases (Kramer 1998, Zahn 2001). Co-operation databases make use of the internet and correspond to virtual public market places for partnerships. Companies willing to co-operate are able to enter their profile into these data bases to offer their capabilities or they can search for partners by defining search criteria. Most of these databases are provided by chambers of commerce. Zahn gives a review on co-operation databases in (Zahn 2001, S.63). To improve the search results, Kramer introduces information broker to identify potential partners by mapping the requested requirements with the offered core competencies.

\subsection{Existing methods to select partners}

After having identified the potential partnerships, the next task is to select the right partners out of this pool. The selection normally bases on an evaluation process using key performance indicators (KPIs). Today, most of the implemented methods for the partner selection are focusing on finding suppliers - nevertheless, there are also approaches available which are able to evaluate the different phases of the product life cycle. The evaluation can be cost-based, quality-based or process-based (Seidl 2002, p.27). In the following, the most relevant concepts for these three categories to support the partner selection are highlighted. Figure 3 maps these concepts with the product life cycle. 


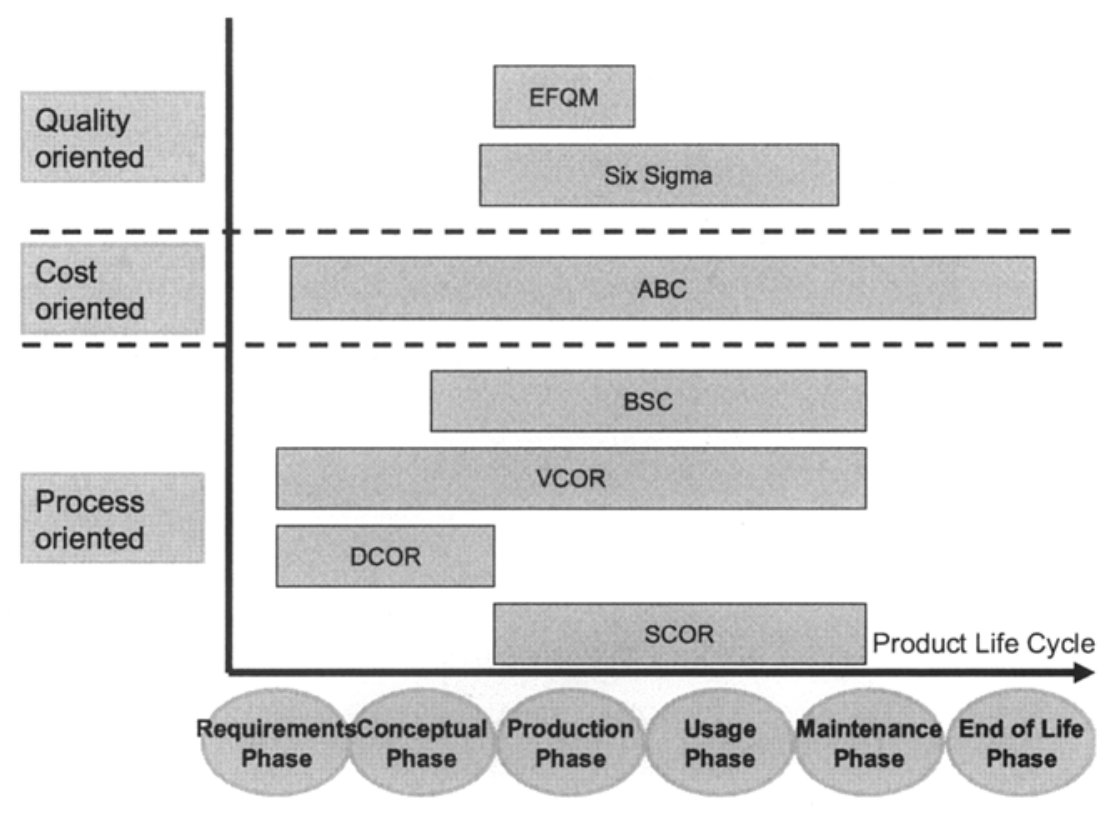

Fig. 3. Concepts for the partner selection in the product life cycle (Seifert 2007, p. 39ff.)

Figure 3 shows that there are specific approaches available to evaluate cost, quality and processes during the different phases of the product life cycle. The most relevant process oriented approaches are the Supply Chain Operations Reference Model (SCOR) for Supply Chain processes, the Design Chain Operations Reference Model (DCOR) for design and conception processes, the Value Chain Operations Reference Model (VCOR) also covering the service development and the Balanced Scorecards (BSC). A well known and often used cost oriented approach is the Activity Based Costing $(\mathrm{ABC})$ able to cover in principle almost all activities related to the product life cycle. Finally, Six Sigma and the European Foundation for Quality Management (EFQM) represent the quality oriented approaches to evaluate industrial processes. Dependent on the phase and the perspective, it is possible to select an appropriate approach for evaluating a potential partners' performance.

\section{Research approach}

The proposed approach is structured into two parts: Part one (chapter 3.1) is the collection of company profiles of co-operation willing companies to acquire data on their offered sub-systems and components as potential contributions to any kind of planned end-product. These company profiles are the basis for the partner identification. By applying key performance indicators referring to the different 
phases of the product life cycle to the profiles, it is also possible to take these profiles in a later step as basis for the partner selection in any phase of the life cycle.

Part two (chapter 3.2) uses these profiles to generate in an iterative way possible product structures for a concrete planned end-product. By searching and combining possible components, different product variants can be developed. Collecting and structuring these potential product contributions, the result are the available alternatives in terms of product structure and partner selection. Following this approach, it is possible to contact and involve potential partners for a new customers' order in a very early phase of the product life cycle. A flexible product design is the main basis for collaborative designs and the derivation of innovative products, because innovation requires the involvement of all available knowledge and experience within a potential network and the structured identification and evaluation of potential solutions.

\subsection{Company profiles to acquire potential product contributions}

To set up company profiles of al co-operation willing companies within the Enterprise Network as starting point to generate flexible product designs, it is important to collect information about the potential partners.

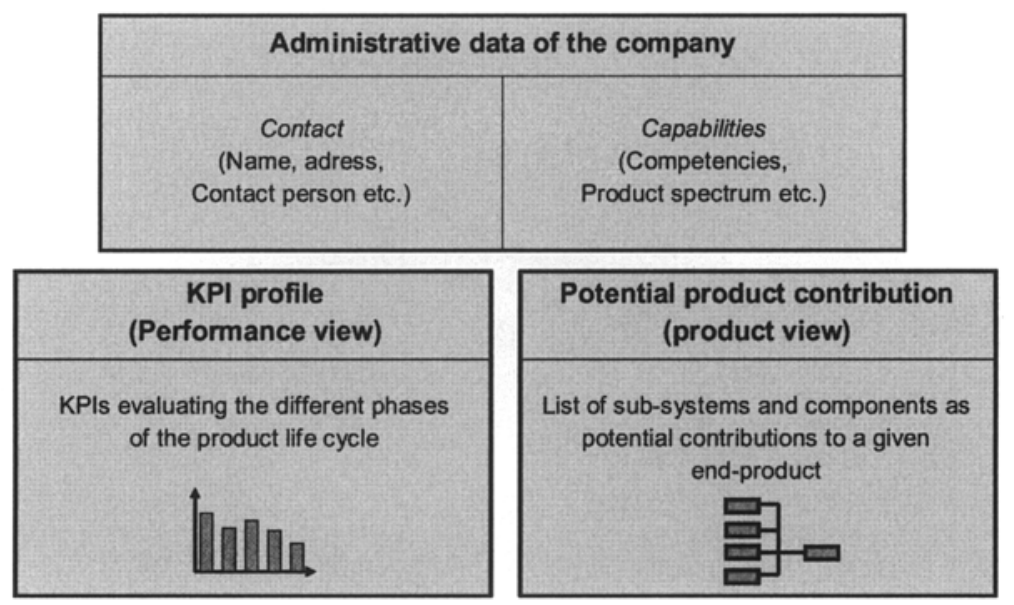

Fig. 4. Components of the company profile

Beside administrative data, information about the offered products have to be collected and stored in a unified, structured way to enable the iterative generation of bill of materials for the desired end-product. The last aspect to be provided by each partner is information about their performance to enable after the partner identification a partner selection on the basis of their KPIs. It is proposed to provide performance data for the different phases of the product life cycle. Figure 4 shows the components of a company profile. 
The offered sub-systems and components as potential contributions to an endproduct provided by a company have to be described in the way that also the necessary inputs to generate this sub-system/component have to be defined. Figure 5 shows a simple example for the description of a sub-system within a company profile.

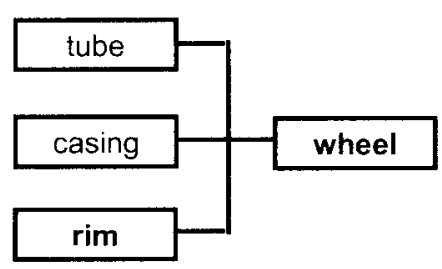

Fig. 5. Components of the company profile

The sub-system provided in this example is a wheel as potential contribution to a bicycle. This sub-system is linked with the necessary input to realise this product which are the rim, casing and tube. Other companies may offer the same sub-system consisting of different inputs which would lead to variants and completely new product designs. Partners providing different variants on the same level enlarge the networks' capability on a horizontal level. Another company may offer the rim as its own potential contribution to a bicycle consisting of the specific input. This kind of vertical contribution is called enrichment of the product scale. Figure 6 shows the difference between horizontal enlargement enabling alternatives and vertical enrichment completing the product structure.

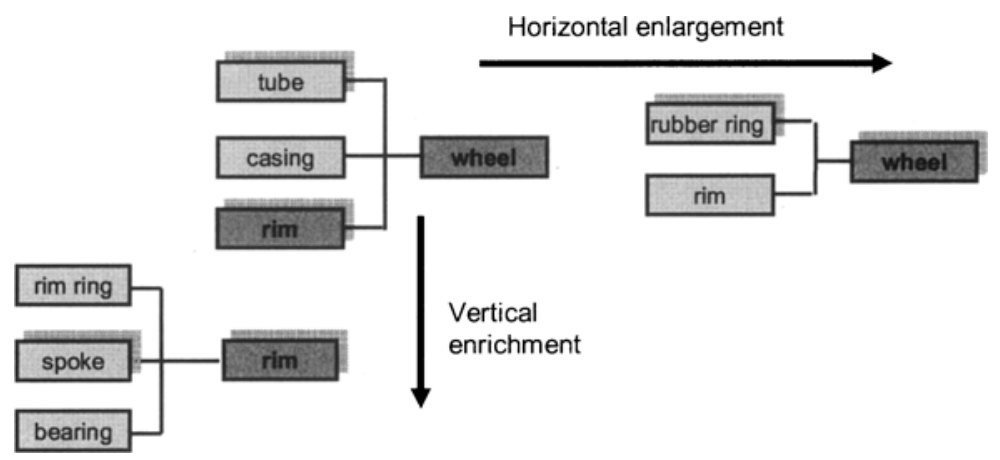

Fig. 6. Horizontal enlargement and vertical enrichment of the product scale

All sub-systems and components of all potential partners have to be provided in this way to be stored in a database. The components are stored within the database independent from their further usage and independent from a specific end-product. In 
the next chapter, it is described how these sub-systems are used to derive complex product designs

\subsection{Iterative generation of possible product structures and derivation of potential partnerships}

The generation of possible product structures on the basis of the available company profiles takes its starting point from the desired end-product. By searching in the company profiles, the first vertical level of product contributions is collected and added to the product structure. Different variants of certain product contributions as described in figure 6 may lead to different potential designs. For each product contribution, the necessary inputs are searched within the available company profiles. Step by step, the alternative product designs can be evaluated and completed step by step. Figure 7 shows the mechanism of the iterative completion with a simple example.

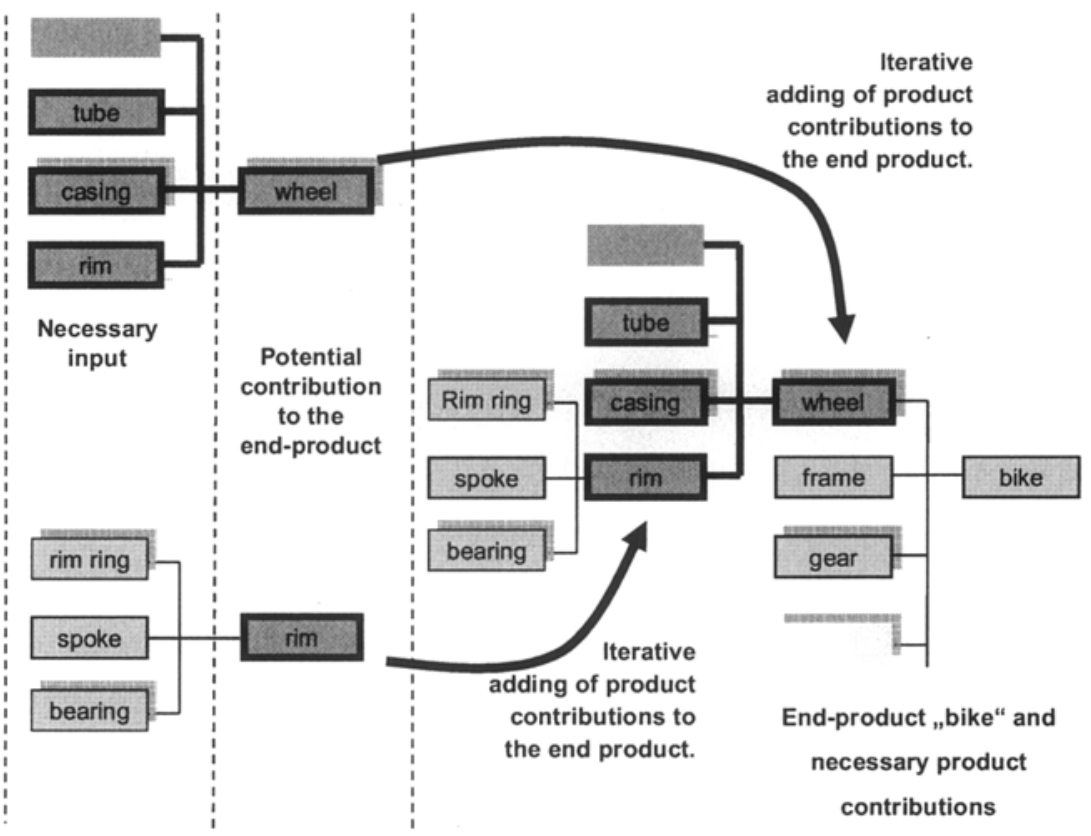

Fig. 7. Iterative generation of a product structure by adding possible product contributions

The described iteration loop is executed as long as there are inputs defined for a product contribution. The result is a multi-dimensional tree structure containing all potential product structures provided by the gathered company profiles. On the basis of the performance indicators, it is now possible to evaluate the potential consortia and to select promising partners to realise the requested end-product. 
This tree supports Enterprise Networks not only to identify alternative product designs and to evaluate partnerships. In the case that needed product contributions can't be covered by the capabilities of the network, these gaps are the impact to concretize the strategic competence development of the co-operation willing partners. Missing competencies and resources can be identified already during the early conceptual phase and suitable additional partners can be searched immediately. This improves the reactivity of the consortium and ensures the permanent offering ability.

\section{Conclusion}

The presented method demonstrated how different product designs can be evaluated in the conceptual phase of the product life cycle and how these alternatives can support the early involvement of promising partners in the product specification. This approach differs from many approaches in practice which require a concrete product design as starting point for the consortium building. The knowledge about potential product variants and available alternatives in the partner selection is a crucial asset to be able to compensate a sudden loss of delivery of a certain partner as fast as possible. The preparedness to generate alternative designs and to involve alterative partners is very important for engineer-to-order products where very late design changes may become relevant in case of changing customer wishes or in case of unpredictable technical problems or malfunctions.

The participation of potential partners in the specification phase and the methodological identification of beneficial partnerships enable the consideration of the available knowledge and experience of these potential partners which is the basis for the development of innovative, competitive products and successful offers. Companies having the chance to participate already in the collaborative product design are in a better position to prepare themselves for the order fulfillment which improves the ability of the Enterprise Network to place offers. Thee ability to provide excellent solutions for customer specific demands and to decline leading offers are crucial for the success of an Enterprise Network - because the production phase and its optimization which is an aspect addressed by many research works, can only take place after a successful and accepted offer after the contract negotiation with the customer.

\section{References}

Boutellier, Roman: Konkurrenz der Logistikketten, in Logistik Heute, Ausgabe Mai 1999

Höbig, Michael: Modellgestützte Bewertung der Kooperationsfähigkeit produzierender Unternehmen, Hannover 2002

Kemmner, Götz-Andreas, Gillessen, Andreas: Virtuelle Unternehmen - Ein Leitfaden zum Aufbau und zur Organisation einer mittelständischen Unternehmenskooperation, Heidelberg 1999 
Kramer, Peter: Die Virtualisierung der Unternehmung: Prozesse, Strukturen und Instrumente eines "grenzenlosen" strategischen Konzeptes, Basel 1998

Linde, Frank: Virtualisierung von Unternehmen - Wettbewerbspolitische Implikationen, Gabler Verlag, Wiesbaden 1997.

Mertins, Peter; Faisst, Wolfgang: Virtuelle Unternehmen - eine Organisationsstruktur für die Zukunft?, in: technologie+management, Nr.2, 1995

Seidl, Jörg: Business Process Performance-Modellbezogene Beurteilung und Ansätze zur Optimierung, in: HMD Praxis der Wirtschaftsinformatik, Heft 227, S.27-35, Oktober 2002

Seifert, Marcus: Unterstützung der Konsortialbildung in Virtuellen Organisationen durch prospektives Performance Measurement, Bremen 2007

Sydow, Jörg: Strategische Netzwerke: Evolution und Organisation, Gabler Verlag, Wiesbaden 2002

Zahn, Erich: Wachstumspotenziale kleiner und mittlerer Dienstleister: Mit Dienstleistungsnetzwerken zu Full-Service Leistungen, Stuttgart 2001 